\title{
Industrial Aplication of Catalytic Systems for $n$-Heptane Isomerization
}

\author{
Laura Olivia Alemán-Vázquez ${ }^{1, *}$, José Luis Cano-Domínguez ${ }^{2}$, Enelio Torres-García ${ }^{2}$ and \\ José Roberto Villagómez-Ibarra ${ }^{3}$
}

1 Transformation Processes Program, Mexican Petroleum Institute, Pachuca- Cd Sahagún Road km 7.5, Canacintra Industrial Park, Mineral de la Reforma, Hgo. 42186, Mexico

2 Transformation Processes Program, Mexican Petroleum Institute, Eje Central Lázaro Cárdenas Norte 152, San Bartolo Atepehuacan, México D. F. 07730, Mexico

3 Chemical Research Center, Hidalgo State University, Pachuca-Tulancingo Road km 4.5, Mineral de la Reforma, Hgo. 42076, Mexico

* Author to whom correspondence should be addressed; E-Mail: laleman@imp.mx; Tel.: +771-7170615; Fax: +771-7163059.

Received: 5 July 2011 / Accepted: 12 July 2011 / Published: 14 July 2011

\begin{abstract}
The ideal gasoline must have a high pump octane number, in the 86 to 94 range, and a low environmental impact. Alkanes, as a family, have much lower photochemical reactivities than aromatics or olefins, but only the highly branched alkanes have adequate octane numbers. The purpose of this work is to examine the possibilities of extending the technological alternative of paraffin isomerization to heavier feedstocks (i.e., $n$-heptane) using non-conventional catalytic systems which have been previously proposed in the literature: a Pt/sulfated zirconia catalyst and a molybdenum sub-oxide catalyst. Under the experimental conditions at which these catalysts have been evaluated, the molybdenum sub-oxide catalyst maintains a good activity and selectivity to isomerization after $24 \mathrm{~h}$, while the Pt/sulfated zirconia catalyst shows a higher dimethylpentanes/methylhexanes ratio, probably due to a lower operating temperature, but also a high formation of cracking products, and presents signs of deactivation after $8 \mathrm{~h}$. Though much remains to be done, the performance of these catalysts indicates that there are good perspectives for their industrial application in the isomerization of $n$-heptane and heavier alkanes.
\end{abstract}

Keywords: molybdenum sub-oxides; sulfated zirconia; catalyst; $n$-heptane isomerization; X-ray diffraction; Raman spectroscopy 


\section{Introduction}

In the formulation of clean gasolines for today's engines, attention must be given to the technical and environmental quality of these fuels. The ideal gasoline must have a high pump octane number, in the 86 to 94 range, and a low environmental impact. Alkanes, as a family, have much lower photochemical reactivities than aromatics or olefins, but only the highly branched alkanes have adequate octane numbers. Since the alkanes present in the gasoline fraction of crude oils are predominantly linear or monobranched, they must be converted into highly branched isomers through the isomerization and reforming processes. Therefore, the isomerization of butane, pentane and hexane are important technologies for improving the octane number of gasolines in petroleum refining, but this technology has not been applied to $n \mathrm{C}_{7}$ and heavier alkanes because the formation of cracking products becomes too high as conversion increases. The interest in the production of clean gasolines with high octane numbers has led to the search for new solid catalysts with improved selectivity for $n \mathrm{C}_{7}+$ isomerization (Tbales 1 and 2).

Table 1. Photochemical reactivity for pure components.

\begin{tabular}{cc}
\hline Hydrocarbons & Ozone Production $\left(\mathbf{g ~ O}_{3} / \mathbf{g}_{\text {Hydrocarbon})}\right.$ \\
\hline ALKANES & 1.040 \\
$n$-pentane & 0.980 \\
$n$-hexane & 0.810 \\
$n$-heptane & 0.610 \\
$n$-octane & 0.540 \\
$n$-nonane & \\
BRANCHED ALKANES & 1.380 \\
2-methylbutane & 1.080 \\
2-methylhexane & 0.960 \\
2-methylheptane & 1.500 \\
2,4-dimethylhexane & 1.600 \\
2,2,4-trimethylpentane & \\
ALKENES & 6.220 \\
1-pentene & 5.290 \\
1-octene & 5.290 \\
3-octene & 4.420 \\
4-methyl-1-pentene & \\
AROMATICS & 2.730 \\
Toluene & 2.700 \\
Ethylbenzene & 7.380 \\
$m$-xylene & 7.380 \\
$p$-xylene &
\end{tabular}

Compounds of groups V, VI and VII transition metals have been widely used as catalysts for the isomerization of $n$-alkanes. The carbides of tungsten and molybdenum are characterized by their high thermal stability and surface reactivity in heterogeneous catalysis. It has been shown that the oxidation of these carbides leads to active and selective materials for the isomerization of alkanes [1-3]. Molybdenum sub-oxides have been prepared by direct reduction of $\mathrm{MoO}_{3}$ with a carbon-rich source at 
temperatures around $623 \mathrm{~K}$ [1-3]. The reduction of $\mathrm{MoO}_{3}$, during which different molybdenum suboxide phases are formed, is the crucial step in the formation of active catalysts for the isomerization of alkanes and has been widely studied [4-7]. Ledoux et al. have suggested that the active phase for alkanes isomerization in this catalyst is a carbon-containing molybdenum sub-oxide, or molybdenum oxycarbide $\left(\mathrm{MoO}_{\mathrm{x}} \mathrm{C}_{\mathrm{y}}\right)$, where carbon atoms fill oxygen vacancies in the course of the catalyst activation, and that the isomerization reaction proceeds through a bond-shift mechanism via a metallocyclobutane intermediate. However, studies carried out by Iglesia et al. [8] on an analogous tungsten catalyst have shown that the isomerization reaction proceeds through the conventional bifunctional mechanism, with dehydrogenation-hydrogenation on metallic sites $\left(\mathrm{WC}_{\mathrm{x}}\right)$ and $\mathrm{C}-\mathrm{C}$ bond rearrangement on acid sites $\left(\mathrm{WO}_{\mathrm{x}}\right)$.

Table 2. Octane numbers of heptane isomers.

\begin{tabular}{lccc}
\hline C $_{7}$ ALKANES & \multicolumn{3}{c}{ OCTANE NUMBERS } \\
\cline { 2 - 4 } & Research & Motor & Pump \\
\hline 2,2,3-trimethyl butane & 112.10 & 101.30 & 106.70 \\
2,2-dimethyl pentane & 92.80 & 95.60 & 94.20 \\
2,4-dimethyl pentane & 83.10 & 83.80 & 83.45 \\
3,3-dimethyl pentane & 80.80 & 86.60 & 83.70 \\
2,3-dimethyl pentane & 91.10 & 88.50 & 89.80 \\
2-methyl hexane & 42.40 & 46.40 & 44.40 \\
3-methyl hexane & 52.00 & 55.80 & 53.90 \\
3-ethyl pentane & 65.00 & 69.30 & 67.15 \\
$n$-heptane & 0.00 & 0.00 & 0.00 \\
\hline
\end{tabular}

The oxidation state of Mo in the molybdenum suboxides catalyst affects its acidity [9] and reduction with hydrogen has substantial effects on the surface acidity and catalytic activity of this catalyst in the isomerization of heptanes [10].

On the other hand, some solid superacid catalysts are known to catalyze the skeletal isomerization of hydrocarbons at low temperatures, but these catalysts tend to deactivate quickly. In particular, sulfated zirconia (SZ) is a very strong solid acid that is able to catalyze the isomerization of $n$-hexane at room temperature, even in the absence of metal sites, but undergoes a very fast deactivation. Several postulates have been offered to explain the rapid catalyst deactivation, including loss of sulfur, change in sulfur oxidation state, transformation of the crystalline structure and deposition of hydrocarbon fragments. The sulfur content could influence the catalyst's crystalline structure and activity [11,12]; when amorphous zirconium hydroxide is treated with sulfate groups, the crystallization process is retarded [13], as sulfate groups relieve some surface energy, thereby stabilizing the tetragonal phase. It has been observed that the addition of platinum increases the stability of SZ catalysts [14-17] and the presence of hydrogen during the reaction is essential to maintain their catalytic activity. The role of platinum in the presence of hydrogen is still a controversial issue; some authors suggest that strong protonic acidity is generated via dissociation and spillover of hydrogen species and the conversion of hydrogen atoms into hydrides, accelerating the desorption of the carbenium intermediates $[17,18]$.

Alkane isomerization on $\mathrm{Pt} / \mathrm{SZ}$ proceeds via chain transfer pathways, with a chain initiation step involving loss of hydrogen from alkanes, a carbenium ion isomerization step and carbenium ions 
propagation by hydrogen transfer from a neutral molecule to a carbocation, in which an isomerized carbocation is removed from the surface and replaced by a new carbocation. Carbocations desorption is slow and limited by the rate of hydrogen transfer, leading to long surface residence times and a high probability that cracking via $\beta$-scission reactions occurs, particularly for $n$-heptane and higher alkanes, for which oligomerization is not required for the $\beta$-scission reaction to proceed. The surface isomerization step is quasi-equilibrated and the surface is almost saturated with carbocations at steadystate [17]. These characteristics of the Pt/SZ catalysts indicate that if the desorption rate can be increased, the cracking selectivity could be reduced while maintaining a good approach to equilibrium in the reaction product isomers distribution. It has been shown that the addition of small amounts of adamantane $(0.8 \mathrm{wt} \%)$ to $n$-heptane increases isomerization rates by a factor of 3 and decreases cracking rates, resulting in a five-fold improvement in the isomerization/cracking selectivity ratio [17]. Acid strength is probably the most important factor in isomerization activity and the importance of Bronsted acid sites has been demonstrated. The surface structure of Pt/SZ has been studied in order to understand the nature of the active sites, and various structures have been proposed of the involved species such as:

(a) The strong acidity of sulfated zirconia has been attributed to the electron-withdrawing anion groups, which lead to coordinatively unsaturated and electron defficient metal centers that behave as strong Lewis acid sites. Water vapor titrates such Lewis sites and converts them to Bronsted acids with very reactive protons [17].

(b) Arata and Hino [19] proposed that water adsorption generates the Lewis and Bronsted acid sites responsible for the catalytic activity, which was confirmed by IR-spectroscopy using pyridine as the test molecule.

(c) Yamaguchi [20], using IR-spectroscopy, showed that superacid centers are Lewis sites associated to the metallic cation. Acid strength of these sites is intensified by the inductive effect of the electrons of the double bond in the $\mathrm{S}=\mathrm{O}$ structure.

(d) Babou et al. [21] considered the acid sites of the sulfated zirconia as $\mathrm{H}_{2} \mathrm{SO}_{4}$ molecules supported on the zirconia surface, which can be reversibly hydrated. At high dehydration conditions an adsorbed $\mathrm{SO}_{3}$ species with a high Lewis acidity is obtained. In an intermediate hydration stage, the presence of $\mathrm{H}_{3} \mathrm{O}^{+}$and $\mathrm{HSO}_{4}{ }^{-}$species promote a high protonic Bronsted acid strength. This reversible effect of water is important for catalytic applications because it modifies the system acidity.

Our research is focused on $n$-heptane and higher alkanes isomerization with non-commercial catalysts for improving the octane number of gasolines. The present work describes the synthesis, characterization and evaluation of both the $\mathrm{Pt} / \mathrm{SZ}$ and the molybdenum sub-oxide catalytic systems for $n$-heptane isomerization, two of the most promising new catalysts proposed for paraffins isomerization.

\section{Results and Discussion}

The specific surface area of the $\mathrm{Pt} / \mathrm{SZ}$ catalyst was $306 \mathrm{~m}^{2} / \mathrm{g}$ before calcination and after calcination it decreased to $129 \mathrm{~m}^{2} / \mathrm{g}$. This decrease can be related to densification of the $\mathrm{ZrO}_{2}$ structure, loss of 
micro- and mesopores and the formation of the monoclinic phase [22]. It is known that transformation from tetragonal to monoclinic zirconia is accompanied not only by a loss in surface area, but also by a corresponding increase in the average crystallite size [23,24]. By contrast, the specific surface area of the pre-activated molybdenum sub-oxide catalyst after $4 \mathrm{~h}$ of reduction with a mixture of $\mathrm{H}_{2} / n \mathrm{C}_{7}$ increases from less than $20 \mathrm{~m}^{2} / \mathrm{g}$ to $53 \mathrm{~m}^{2} / \mathrm{g}$.

$\mathrm{X}$-ray difraction of the $\mathrm{Pt} / \mathrm{SZ}$ catalyst before calcination shows only broad bands in the $18-40^{\circ}$ and $40-70^{\circ}$ ranges in angular displacement $(2 \theta)$, indicative of the small size of the crystallites or of amorphous behavior. Highly crystalline materials were obtained after calcination at $873 \mathrm{~K}$ (Figure 1). Both monoclinic $\left(\mathrm{M}: 2 \theta \approx 28^{\circ}\right)$ and metastable tetragonal $\left(\mathrm{T}: 2 \theta \approx 30^{\circ}\right)$ phases are detected; the latter is predominant [25]. These results suggest that when amorphous zirconium hydroxide is impregnated with sulfate groups, these groups stabilize the metastable tetragonal phase of $\mathrm{ZrO}_{2}$ and delay the sintering process [25]. The tetragonal phase has been reported to be the active phase for isomerization in SZ catalysts.

Figure 1. X-ray difraction of the $\mathrm{Pt} / \mathrm{SZ}$ catalyst after calcination at $873 \mathrm{~K}$.

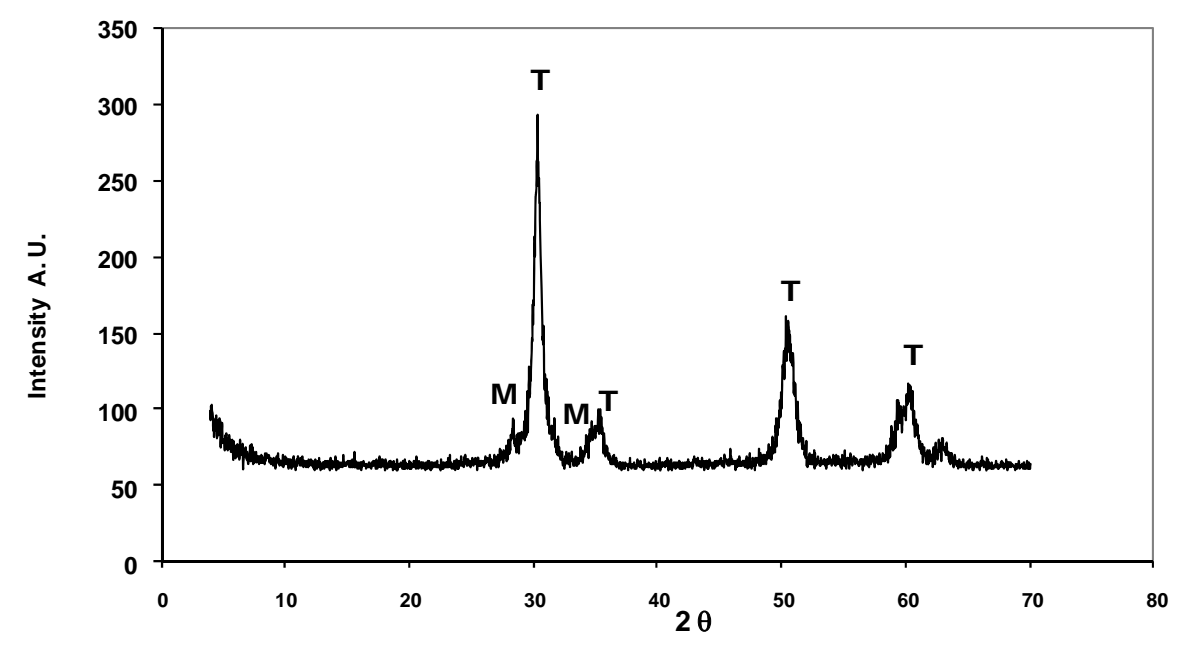

Raman spectroscopy was used to study the structure of sulfated zirconia at a molecular length scale. Figure 2 shows the Raman spectrum of the $\mathrm{SO}_{x}-\mathrm{ZrO}_{2}$ sample. The tetragonal and monoclinic $\mathrm{ZrO}_{2}$ polymorphs presented Raman bands in the $100-760 \mathrm{~cm}^{-1}$ region. In general, the typical tetragonal phase of $\mathrm{ZrO}_{2}$ can be identified from the bands at 317,455 and $640 \mathrm{~cm}^{-1}$, whereas the bands at 223, 560 and $622 \mathrm{~cm}^{-1}$ are assigned to the monoclinic phase [22]. The bands at 1000 and $1031 \mathrm{~cm}^{-1} \mathrm{can}$ be attributed to $\mathrm{S}-\mathrm{O}$ modes of the sulfate groups (adsorbed species of $\mathrm{SO}_{3}$ and $\mathrm{H}_{2} \mathrm{SO}_{4}$ ). The band located at $1070 \mathrm{~cm}^{-1}$ can also be attributed to $\mathrm{S}-\mathrm{O}$ stretching modes, but in polynucleate sulfate groups.

XRD patterns of the molybdenum sub-oxides obtained by reduction with $\mathrm{H}_{2} / n \mathrm{C}_{7}$ at $643 \mathrm{~K}$ and 18.5 bar for 4, 12 and $24 \mathrm{~h}$ are presented in Figure 3. The XRD pattern of the starting orthorhombic $\mathrm{MoO}_{3}$ (JCPDS data file no. 05-0508) is included for better understanding. Besides $\mathrm{MoO}_{3}$, new phases were detected after the reduction process. One of the phases is unequivocally related to the monoclinic $\mathrm{MoO}_{2}$ (JCPDS data file no. 32-671). The low intensity peak at $d_{h k l}=6.1 \AA$ is associated to the most intense reflection line (10-1) of residues of a hydrogen molybdenum bronze $\mathrm{H}_{\mathrm{x}} \mathrm{MoO}_{3}$ (JCPDS data file no. 41-0060). Reflections with interplanar distances at 2.34 and $2.04 \AA$ are associated to the formation 
of a molybdenum sub-oxide with a cubic crystal structure, having an experimental cubic parameter $\mathrm{a}=4.08 \AA$, previously identified as $\mathrm{MoO}$ [26-28].

Figure 2. Raman spectra of $\mathrm{Pt} / \mathrm{SZ}$ catalyst after calcination at $873 \mathrm{~K}$.

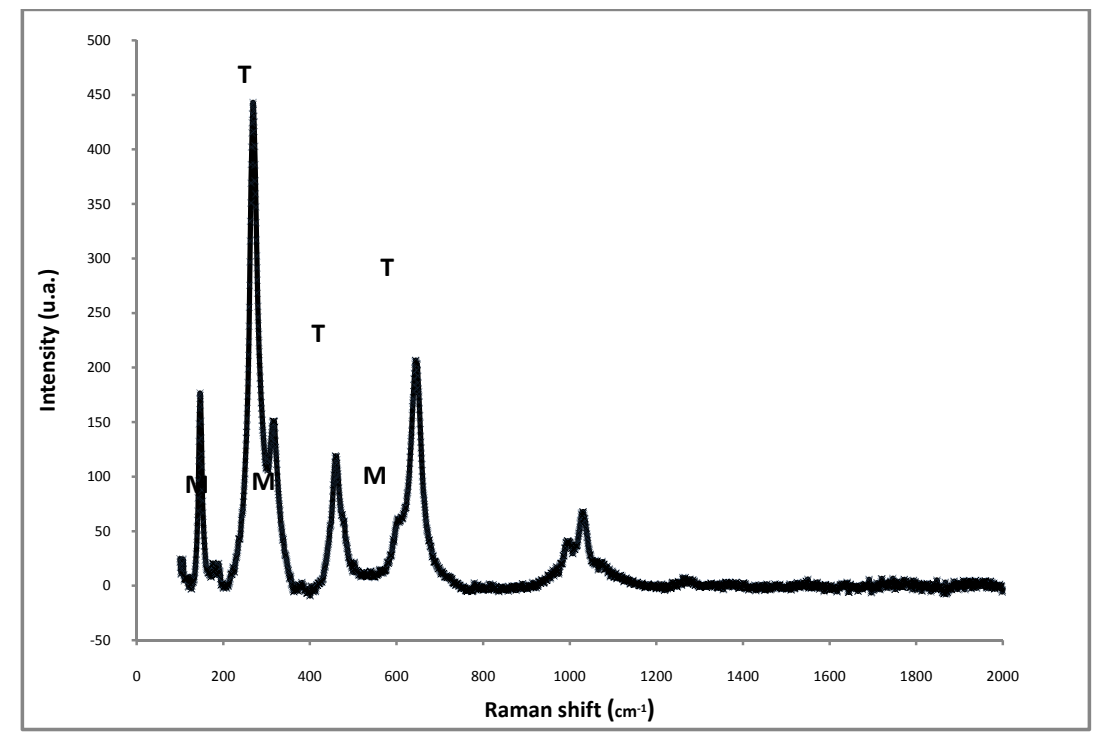

Figure 3. XRD patterns of I) orthorhombic $\mathrm{MoO}_{3}$ (JCPDS data file no. 05-0508) and molybdenum sub-oxides obtained at 4,12 and $24 \mathrm{~h}$ under flow of $\mathrm{H}_{2} / n-\mathrm{C}_{7}$ at $643 \mathrm{~K}$.

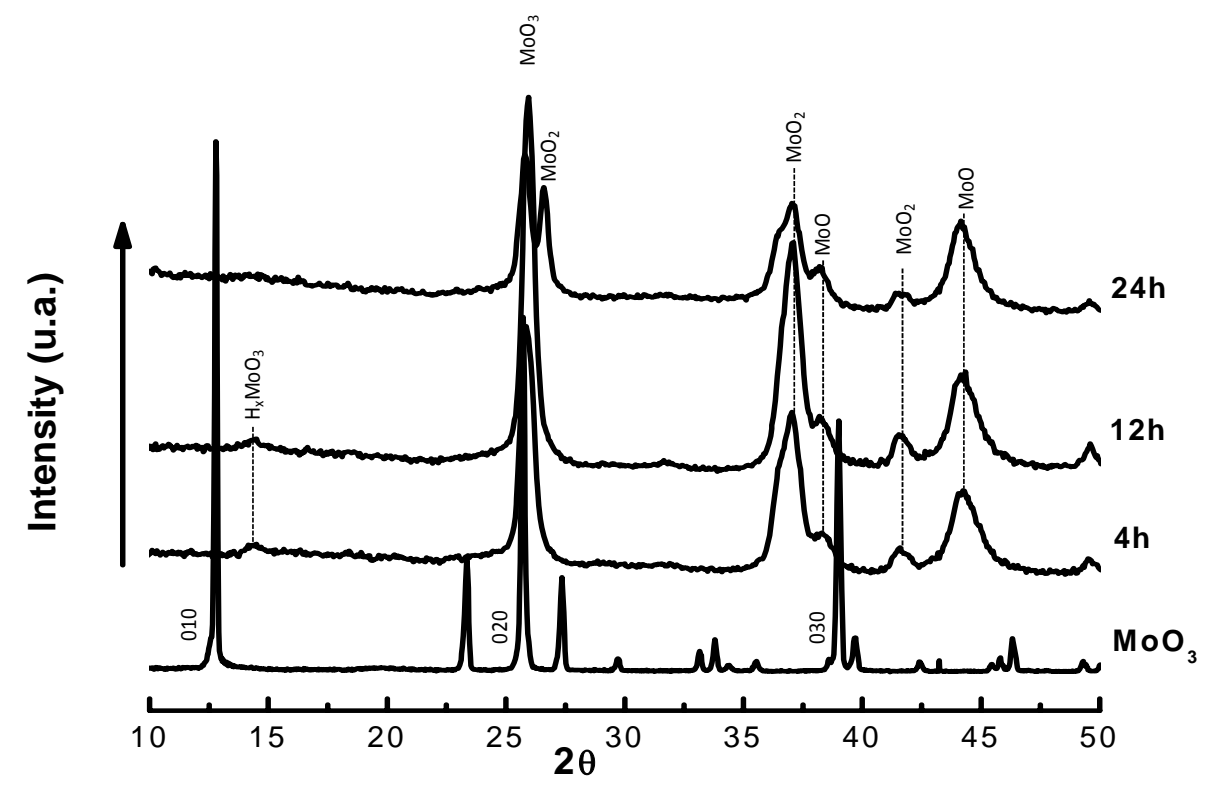

In general, the Raman spectra of the $\mathrm{MoO}_{3}$ samples after treatment with $\mathrm{H}_{2} / n-\mathrm{C}_{7}$ at $643 \mathrm{~K}$ for 4,12 and $24 \mathrm{~h}$ show significant changes in the intensity of the Raman bands, see Figure 4 . These changes are associated with the degree of crystallinity of the samples and the progressively lower oxygen/metal ratio. Raman bands at 666,815 and $990 \mathrm{~cm}^{-1}$ correspond to orthorhombic $\mathrm{MoO}_{3}$, while bands at 486, 568 and $737 \mathrm{~cm}^{-1}$ are characteristic of monoclinic $\mathrm{MoO}_{2}$ obtained during the experiments, which is in agreement with our XRD results. These results suggest that the significant decrease in intensity and resolution of the bands at 815 and $990 \mathrm{~cm}^{-1}$ during reduction is associated to the preferential electrophilic attack of the $\mathrm{H}_{2}$ on the terminal $\pi \mathrm{M}=\mathrm{O}$ bonds along the $\{0 \mathrm{k} 0\}$ planes, with the formation 
of oxygen vacancies and partial reduction of the $\mathrm{Mo}^{+6}$. These vacancies increase the density of surface sites on the basal planes and lead to the formation of crystallographic shear planes during the reduction process. These segments are thought to be catalytically active for chemical reactions, as Mo cations on them are coordinately unsaturated.

Figure 4. Raman spectra of the $\mathrm{MoO}_{3}$ samples after treatment with $\mathrm{H}_{2} / n \mathrm{C}_{7}$ at $643 \mathrm{~K}$ for $4 \mathrm{~h}$ (I), $12 \mathrm{~h}$ (II) and $24 \mathrm{~h}$ (III).



In this work, we carried out the isomerization tests of the $\mathrm{Pt} / \mathrm{SZ}$ and molybdenum sub-oxides catalysts under operating conditions suggested in previous studies. The conversion and products distribution of $n$-heptane isomerization with the Pt/SZ catalyst at $473 \mathrm{~K}$ and at 2, 4, 6 and $8 \mathrm{~h}$ are shown in Table 3. This catalyst showed a maximum conversion around $53 \%$ and a fair amount of isomerization products, with methylhexanes and dimethylpentanes as the main products. The dimethylpentanes/methylhexanes ratio was relatively high $(0.374-0.423)$, probably due to the low reaction temperature, but still far from the thermodynamic equilibrium ratio of 1.8. However, a high formation of cracking products $\left(\mathrm{C}_{1}-\mathrm{C}_{6}\right)$ was observed for this catalyst under these experimental conditions, resulting in relatively low selectivities to isomerization (70\%-78\%). The $n$-heptane conversion decreased from 6 to $8 \mathrm{~h}$ on stream. The causes of their deactivation are still under discussion. The deactivation has been attributed to deposition of polymerized hydrocarbons on the catalyst, causing the coverage of the acid centers by carbonaceous deposits [29], to reduction of $\mathrm{Zr}^{4+}$ to $\mathrm{Zr}^{3+}$ on the surface of the catalysts during the reaction or to the transformation of tetragonal to monoclinic zirconia on the surface of the catalyst [30].

The conversion and products distribution of $n$-heptane isomerization with the molybdenum suboxide catalyst at $643 \mathrm{~K}$ and at 2 to $24 \mathrm{~h}$ are shown in Table 4 . The conversion of $n$-heptane increased during this period and reached a high of $78 \%$ at $24 \mathrm{~h}$. This slow development of the catalyst's activity suggests that the active phase is formed progressively by the reduction of the $\mathrm{MoO}_{3}$ and stabilizes after 12 to $24 \mathrm{~h}$ on stream. No deactivation was observed after $24 \mathrm{~h}$ on stream. The dimethylpentanes/ methylhexanes ratio started around 0.2 and increased to a high of 0.325 after $24 \mathrm{~h}$; this ratio was lower than the one for the $\mathrm{Pt} / \mathrm{SZ}$ catalyst, probably due to the higher reaction temperature $(643 \mathrm{~K})$, for which the thermodynamic equilibrium ratio is close to 1 . The formation of cracking products was moderate up to $24 \mathrm{~h}$ on stream, increasing somewhat after $12 \mathrm{~h}$.

The conversion of $n$-heptane on the molybdenum sub-oxides and $\mathrm{Pt} / \mathrm{SZ}$ catalysts are shown in Figure 5. 
Table 3. Isomerization of $n$-heptane over Pt/SZ catalyst (473 K, 18.5 bar).

\begin{tabular}{lllll}
\hline Time on stream (h) & $\mathbf{2}$ & $\mathbf{4}$ & $\mathbf{6}$ & $\mathbf{8}$ \\
\hline Conversion (wt \%) & 33.33 & 49.35 & 53.23 & 43.47 \\
Selectivity to isomerization (wt \%) & 73.96 & 70.49 & 69.96 & 77.57 \\
Selectivity to cracking (wt \%) & 7.58 & 25.21 & 26.38 & 19.14 \\
Branched isomers (wt \%) & 24.48 & 34.54 & 36.97 & 33.48 \\
Dimethylpentanes & 6.50 & 10.02 & 10.66 & 9.15 \\
Methylhexanes & 17.37 & 23.69 & 25.46 & 23.55 \\
3-ethylpentane & 0.61 & 0.83 & 0.86 & 0.78 \\
Dimethylpentanes/ Methylhexanes & 0.37 & 0.42 & 0.41 & 0.39 \\
Cracked products (wt \%) & & & & \\
C1-C4 & 1.30 & 5.02 & 5.70 & 3.22 \\
C5-C6 & 1.20 & 7.32 & 8.23 & 5.04 \\
\hline
\end{tabular}

Table 4. Isomerization of $n$-heptane over molybdenum sub-oxides catalyst ( $643 \mathrm{~K}, 18.5$ bar).

\begin{tabular}{|l|l|l|l|l|l|l|l|l|l|l|l|l|}
\hline Time on stream (h) & $\mathbf{2}$ & $\mathbf{4}$ & $\mathbf{6}$ & $\mathbf{8}$ & $\mathbf{1 0}$ & $\mathbf{1 2}$ & $\mathbf{1 4}$ & $\mathbf{1 6}$ & $\mathbf{1 8}$ & $\mathbf{2 0}$ & $\mathbf{2 2}$ & $\mathbf{2 4}$ \\
\hline Conversion (wt \%) & 33.21 & 49.84 & 64.36 & 66.85 & 69.31 & 70.24 & 74.21 & 74.43 & 75.43 & 76.39 & 77.45 & 78.01 \\
\hline $\begin{array}{l}\text { Selectivity to } \\
\text { isomeriz. (wt \%) }\end{array}$ & 89.94 & 92.82 & 92.11 & 92.12 & 90.68 & 92.33 & 89.79 & 89.43 & 87.93 & 86.44 & 85.34 & 87.45 \\
\hline $\begin{array}{l}\text { Selectivity to } \\
\text { cracking (wt\%) }\end{array}$ & 7.85 & 4.59 & 7.31 & 7.62 & 9.07 & 7.47 & 9.77 & 10.17 & 11.64 & 12.81 & 14.16 & 11.99 \\
\hline $\begin{array}{l}\text { Branched isomers } \\
\text { (wt \%) }\end{array}$ & 29.66 & 45.94 & 58.87 & 61.15 & 62.41 & 64.40 & 66.17 & 66.10 & 65.86 & 65.57 & 65.63 & 67.74 \\
\hline Dimethylpentanes & 4.67 & 7.44 & 10.72 & 11.59 & 12.36 & 12.98 & 14.31 & 14.44 & 14.70 & 14.89 & 15.29 & 16.07 \\
\hline Methylhexanes & 24.11 & 37.01 & 46.14 & 47.50 & 47.91 & 49.21 & 49.61 & 49.41 & 48.92 & 48.50 & 48.16 & 49.40 \\
\hline 3-ethylpentane & 0.89 & 1.49 & 2.01 & 2.06 & 2.14 & 2.22 & 2.25 & 2.24 & 2.24 & 2.18 & 2.17 & 2.26 \\
\hline $\begin{array}{l}\text { DimethylC } / \\
\text { MethylC } 6\end{array}$ & 0.194 & 0.201 & 0.232 & 0.244 & 0.258 & 0.264 & 0.288 & 0.292 & 0.300 & 0.307 & 0.317 & 0.325 \\
\hline $\begin{array}{l}\text { Cracked products } \\
(w t \%)\end{array}$ & & & & & & & & & & & & \\
\hline $\mathrm{C}_{1}-\mathrm{C}_{4}$ & 1.16 & 1.23 & 1.74 & 1.91 & 2.78 & 2.16 & 3.21 & 3.58 & 4.55 & 5.32 & 6.32 & 4.96 \\
\hline $\mathrm{C}_{5}-\mathrm{C}_{6}$ & 1.43 & 1.04 & 2.93 & 3.15 & 3.46 & 3.05 & 3.99 & 3.94 & 4.17 & 4.40 & 4.57 & 4.33 \\
\hline
\end{tabular}

Figure 5. Conversion of $n$-heptane for Pt/SZ and molybdenum sub-oxide catalysts at 18.5 bar.

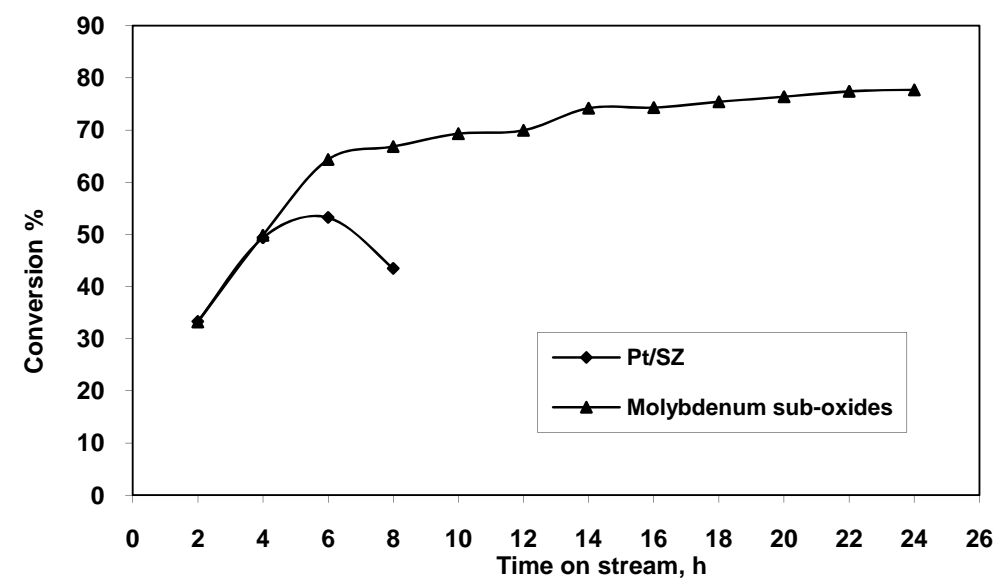




\section{Experimental}

Two isomerization catalysts were synthesized: (i) a Pt/sulfated zirconia (SZ) catalyst, prepared by the precipitation method from zirconium oxychloride; and (ii) a molybdenum sub-oxide catalyst, obtained by reduction of $\mathrm{MoO}_{3}$.

\subsection{Sulfated Zirconia (SZ) Catalyst Preparation}

High-surface-area $\mathrm{ZrO}_{2-x}(\mathrm{OH})_{2 \mathrm{x}}\left(320 \mathrm{~m}^{2} / \mathrm{g}\right.$ ) was prepared by hydrolysis of $\mathrm{ZrOCl}_{2} \cdot 8 \mathrm{H}_{2} \mathrm{O}$ (Aldrich, $98 \%$ purity) by addition of an $\mathrm{NH}_{4} \mathrm{OH}$ solution (J.T. Baker, $28 \mathrm{wt} \%$ ) under agitation, until a $\mathrm{pH}$ value of 10 was reached. The precipitate was filtered and washed repeatedly by re-dispersion with $\mathrm{NH}_{4} \mathrm{OH}$ solution $(\mathrm{pH}=10)$ until elimination of $\mathrm{Cl}^{-}$, and then dried at $383 \mathrm{~K}$ for $24 \mathrm{~h}$. Subsequently, $\mathrm{ZrO}_{2-\mathrm{x}}(\mathrm{OH})_{2 \mathrm{x}}$ was sulfated by impregnation during $4 \mathrm{~h}$ with a $0.07 \mathrm{M}$ solution of $\mathrm{H}_{2} \mathrm{SO}_{4}$ (for a theoretical sulfur concentration of $3 \mathrm{wt} \%$ ). The sulfated material was vacuum filtered and dried at $383 \mathrm{~K}$ for $15 \mathrm{~h}$ and then immersed in an aqueous solution of $\mathrm{H}_{2} \mathrm{PtCl}_{6}$ (Aldrich, $8 \mathrm{wt} \%$ ) to obtain $0.3 \mathrm{wt} \%$ of platinum in the catalyst and stirred during $30 \mathrm{~min}$. The material was dried at $383 \mathrm{~K}$ for $15 \mathrm{~h}$ and calcined at $873 \mathrm{~K}$ for $2 \mathrm{~h}$. The sulfur content in the Pt/SZ catalyst before calcination was determined as $2.95 \mathrm{wt} \%$ and after calcination as $1.18 \mathrm{wt} \%$. The reduction in the sulfur content after calcination may be related to a high proportion of the sulfate ions being on the surface of the catalyst.

\subsection{Molybdenum Sub-Oxides Catalyst Preparation}

A $1 \mathrm{~g} \mathrm{MoO}_{3}$ sample (Fermont, $98 \mathrm{wt} \%$ purity) was placed in a continuous flow stainless steel reactor $(0.9 \mathrm{~cm}$ in diameter) and the temperature was raised to $643 \mathrm{~K}$ under hydrogen flow of $100 \mathrm{~mL} / \mathrm{h}$. The pressure was kept at 18.5 bar. Afterwards, $n$-heptane (Aldrich, 99 wt \% purity) was also fed to the reactor at a rate of $5 \mathrm{~mL} / \mathrm{h}$ during $4 \mathrm{~h}$ using an Eldex metering pump. The hydrogen flow was controlled using a Brooks 5850E mass flow controller.

\subsection{Characterization}

The specific surface areas of the samples were determined by the BET method using a Micromeritics ASAP-2401 system. The $\mathrm{MoO}_{3}$, the molybdenum sub-oxides catalyst and the Pt/SZ catalyst were characterized by X-ray diffraction using a Siemens diffractometer (Model D5000) with $\mathrm{Cu} \mathrm{K} \alpha$ radiation and a $\mathrm{Ni}$ filter. The operating conditions were $30 \mathrm{kV}$ and $20 \mathrm{~mA}$ in the angular range $4-70^{\circ}$ in $2 \theta$. Crystalline phase identification based on XRD patterns was aided by the ICDD-PDF-2 database. The Raman spectra of $\mathrm{MoO}_{3}$, of the molybdenum sub-oxides catalyst and of the Pt/SZ catalyst were obtained in air at room temperature with a double monochromator Raman spectrometer (SPEX Mod. 1403) using an $\mathrm{Ar}^{+}$ion laser which delivered $10 \mathrm{~mW}$ of incident radiation. The excitation line of the laser was $514.5 \mathrm{~nm}$. The Raman signal was detected with a photomultiplier and a standard photon counting system. Total sulfur in the Pt/SZ catalyst was determined by the ASTM D1552 analytical method. 


\subsection{Catalysts Evaluation}

\subsubsection{Isomerization reaction with the $\mathrm{Pt} / \mathrm{SZ}$ catalyst}

A $1 \mathrm{~g}$ sample of this catalyst was placed in a continuous flow stainless steel reactor $(0.9 \mathrm{~cm}$ in diameter) and the temperature was raised to $473 \mathrm{~K}$ under hydrogen flow at a pressure of 18.5 bar. Hydrogen flow $(100 \mathrm{~mL} / \mathrm{h})$ was controlled using a Brooks $5850 \mathrm{E}$ mass flow controller. Then $n$-heptane (Aldrich, $99 \mathrm{wt} \%$ purity) was fed to the reactor at a rate of $5 \mathrm{~mL} / \mathrm{h}$ using an Eldex metering pump, at the pressure above indicated.

\subsubsection{Isomerization reaction with the molybdenum sub-oxides catalyst}

The isomerization reaction was carried out under the same flows and conditions used for the molybdenum sub-oxide preparation $(643 \mathrm{~K}, 18.5 \mathrm{bar})$. The activity and selectivity of both catalysts for the isomerization of $n$-heptane were evaluated at different reaction times with on-line analysis of the reaction products using an Agilent 6890 gas chromatograph equipped with the PIANO software. The conversion and selectivity were calculated using the following equations:

$$
\begin{gathered}
\text { Conversion }=\frac{n C_{7}^{o}-n C_{7}^{f}}{n C_{7}^{o}} \frac{w t}{w t} \times 100 \\
\text { Selectivity to isomerization }=\frac{C_{7} \text { isomers }}{n C_{7}^{o}-n C_{7}^{f}} \frac{w t}{w t} \times 100
\end{gathered}
$$

where $n C_{7}^{0}$ and $n C_{7}^{f}$ are the concentration of $n C_{7}$ at the beginning of the test and at each sampling time respectively.

\section{Conclusions}

The Pt/SZ catalyst (1.18 wt \% sulfur, $0.3 \mathrm{wt} \% \mathrm{Pt}$ ) showed a better dimethylpentanes/methylhexanes ratio (0.374-0.423), a maximum $n$-heptane conversion of $53 \%$ and relatively low selectivities to isomerization $(70 \%-78 \%)$, due to a high formation of cracking products. This catalyst presented signs of deactivation after $8 \mathrm{~h}$ on stream.

The molybdenum sub-oxide catalyst showed a good activity, reaching a maximum $n$-heptane conversion of $78 \%$ after $24 \mathrm{~h}$ on stream. No deactivation was observed for this catalyst. The selectivity to isomerization was relatively high $(85 \%-93 \%)$ and the formation of cracking products was moderate up to $24 \mathrm{~h}$ on stream. However, the dimethylpentanes/methylhexanes ratio was relatively low ( 0.325 at $24 \mathrm{~h})$.

Though much remains to be done, these results indicate that these catalysts have good perspectives for their industrial application of isomerization to $n$-heptane and heavier paraffins.

\section{References and Notes}

1. Ledoux, M.J.; Del Gallo, P.; Pham-Huu, C.; York, A.P.E. Molybdenum oxycarbide isomerization catalysts for cleaner fuel production. Catal. Today 1996, 27, 145-150. 
2. Blekkan, E.A.; Pham-Huu, C.; Ledoux, M.J.; Guille, J. Isomerization of $n$-heptane on an oxygenmodified molybdenum carbide catalyst. Ind. Eng. Chem. Res. 1994, 33, 1657-1664.

3. Ledoux, M.J.; Guille, J.; Pham-Huu, C.; Blekkan, E.A.; Peschiera, E. Process for the isomerisation of straight hydrocarbons containing at least 7 carbon atoms using catalysts with a base of molybdenum oxycarbide. U.S. Patent 5,576,466, 1996.

4. Ledoux, M.J.; Meunier, F.; Heinrich, B.; Pham-Huu, C.; Harlin, M.E.; Krause, A.O.I. Part I. $n$-Butane dehydrogenation on unsupported carbon modified $\mathrm{MoO}_{3}\left(\mathrm{MoO}_{\mathrm{x}} \mathrm{C}_{\mathrm{y}}\right)$ : Effect of stream on the catalyst stability. Appl. Catal. A 1999, 181, 157-170.

5. Delporte, P.; Meunier, F.; Pham-Huu, C.; Vennegues, P.; Ledoux, M.J.; Guille, J. Physical characterization of molybdenum oxycarbide catalyst: TEM, XRD and XPS. Catal. Today 1995, 23, 251-267.

6. Delporte, P.; Pham-Huu, C.; Ledoux, M.J. Effect of the reaction temperature and hydrocarbon partial pressure on the activity of carbon-modified $\mathrm{MoO}_{3}$ for n-hexane isomerization. Appl. Catal. A 1997, 149, 151-180.

7. Bouchy, C.; Pham-Huu, C.; Heinrich, B.; Chaumont, C.; Ledoux, M.J. Microstructure and characterization of a highly selective catalyst for the isomerization of alkanes: A molybdenum oxycarbide. J. Catal. 2000, 190, 92-103.

8. Iglesia, E.; Baumgartner, J.E.; Ribeiro, F.H.; Boudart, M. Bifuntional reactions of alkanes on tungsten carbides modified by chemisorbed oxygen. J. Catal. 1991, 131, 523-544.

9. Brown, S.C.; Hargreaves, J.S.J.; Taylor, S.H. A study of "superacidic" $\mathrm{MoO}_{3} / \mathrm{ZrO}_{2}$ catalysts for methane oxidation. Catal. Lett. 1999, 57, 109-113.

10. Scheithauer, M.; Grasselli, R.K.; Knözinger, H. Genesis and structure of $\mathrm{WOx} / \mathrm{ZrO}_{2}$ solid acid catalysts. Langmuir 1998, 14, 3019-3029.

11. Zalewski, D.J.; Saeed, A.; Doolin, P.K. Characterization of catalytically active sulfated zirconia. Catal. Today 1999, 53, 419-432.

12. Alemán-Vázquez, L.O.; Mariel-Reyes, P.R.; Cano-Domínguez, J.L. The effect of sulfates concentration in sulfated zirconia (SZ) catalysts on $n$-heptane isomerization. Pet. Sci. Tech. 2010, 28, 374-381.

13. Normair, C.J.; Goulding, P.A.; McAlpine, I. Role of anions in the surface area. Catal. Today 1994, 20, 313-317.

14. Sameer, V.; Wolf, E.E. A highly active and stable platinum-modified sulfated zirconia catalyst 1. Preparation and activity for $n$-pentane isomerization. Appl. Catal. A 2004, 264, 117-124.

15. Sayari, A.; Dicko, A. The state of platinum in Pt on sulfated zirconia superacid catalysts. J. Catal. 1994, 145, 561-564.

16. Grau, J.M.; Parera, J.M. Single and composite bifunctional catalysts of $\mathrm{H}-\mathrm{MOR}$ or $\mathrm{SO}_{4}{ }^{2-}-\mathrm{ZrO}_{2}$ for $n$-octane hydroisomerization-cracking. Influence of the porosity of the acid component. Appl. Catal. A: General 1997, 162, 17-27.

17. Iglesia, E.; Soled, S.L.; Kramer, G.M. Isomerization of alkanes on sulfated zirconia: Promotion by Pt and by adamantyl hydride transfer species. J. Catal. 1993, 144, 238-253.

18. Comelli, R.A.; Finelli, Z.R.; Vaudagna, S.R. Hydroisomerization of $n$-hexane on $\mathrm{Pt} / \mathrm{SO}_{4}{ }^{2-}-\mathrm{ZrO}_{2}$ : Effect of total and hydrogen partial pressure. Catal. Lett. 1997, 45, 227-231. 
19. Hino, M.; Kobayashi, S.; Arata, K. Reactions of butane and isobutene catalyzed by zirconium oxide treated with sulfate ion. J. Am. Chem. Soc. 1979, 101, 6439-6441.

20. Yamaguchi, T. Application of $\mathrm{ZrO}_{2}$ as a catalyst and a catalyst support. Catal. Today 1994, 20, 199-217.

21. Babou, F.; Coudurier, G.; Vedrine, J.C. Acidic properties of sulfated zirconia: An infrared spectroscopic study. J. Catal. 1995, 152, 341-349.

22. Garin, F.; Andriamasinoro, D.; Abdulsamad, A.; Sommer, J. Conversion of butane over the solid superacid $\mathrm{ZrO}_{2} / \mathrm{SO}_{4}{ }^{2-}$ in the presence of hydrogen. J. Catal. 1991, 131, 199-203.

23. Benaïssa, M.; Santiesteban, J.G.; Díaz, G.; Chang, C.D. Interaction of sulfate groups with the surface of zirconia: An HRTEM characterization study. J. Catal. 1996, 161, 694-703.

24. Jouanne, M.; Morhange, J.F.; Kanehisa, M.; Haro-Poniatowski, E.; Fuentes, G.A.; Torres, E.; Hernández-Tellez, E. Structural transformation in nanosized zirconium oxide. Phys. Rev. B 2001, 64, 154041-154047.

25. Torres-García, E.; Peláiz-Barranco, A.; Vázquez-Ramos, C.; Fuentes, G.A. Thermal and structural characterization of the $\mathrm{ZrO}_{2-\mathrm{x}}(\mathrm{OH})_{2 \mathrm{x}}$ to $\mathrm{ZrO}_{2}$ transition. J. Mater. Res. 2001, 16, 2209-2212.

26. Vera, C.R.; Pieck, C.L.; Shimizu, K.; Parera, J.M. Tetragonal structure anionic vacancies and catalytic activity of $\mathrm{SO}_{4}{ }^{2-}-\mathrm{ZrO}_{2}$ catalysts for n-butane isomerization. Appl. Catal. A: General 2002, 230, 137-151.

27. Torres-García, E.; Rodríguez-Gattorno, G.; Ascencio-Gutierrez, J.A.; Alemán-Vázquez, L.O.; Cano-Domínguez, J.L.; Martínez-Hernández, A.; Santiago-Jacinto, P. New insights on molybdenum suboxide: Nature of carbons in isomerization reactions. J. Phys.Chem. B 2005, 109, 17518-17525.

28. Rodríguez-Gattorno, G.; Martínez-Hernández, A.; Aleman-Vázquez, L.O.; Torres-García, E. Structural and thermal study of carbon-modified molybdenum sub-oxide catalysts. Appl. Catal. A: General 2007, 321, 117-124.

29. Resofszki, G.; Muhler, M.; Sprenger, S.; Wild, U.; Paál, Z. Electron spectroscopy of sulfated zirconia, its activity in $n$-hexane conversion and possible reasons of its deactivation. Appl. Catal. A: General 2003, 240, 71-81.

30. Ahmad, R.; Melsheimer, J.; Friederike, C.; Jentoft, F.C.; Schlögl, R. Isomerization of n-butane and of n-pentane in the presence of sulfated zirconia: Formation of surface deposits investigated by in situ UV-vis diffuse reflectance spectroscopy. J. Catal. 2003, 218, 365-374.

Sample Availability: Not available.

(C) 2011 by the authors; licensee MDPI, Basel, Switzerland. This article is an open access article distributed under the terms and conditions of the Creative Commons Attribution license (http://creativecommons.org/licenses/by/3.0/). 